\title{
A Self-Regulation Hypothesis of Coping with an Unjust World: Ego-Depletion and Self-Affirmation as Underlying Aspects of Blaming of Innocent Victims
}

\author{
Annemarie Loseman · Kees van den Bos
}

Published online: 15 March 2012

(C) The Author(s) 2012. This article is published with open access at Springerlink.com

\begin{abstract}
People have a need to Belief in a Just World (BJW) in which people get what they deserve. When people are confronted with an event which threatens this BJW (e.g. when they witness a girl falling victim to rape), people try to maintain their existing beliefs, for example, by blaming the innocent victim for her ill fate. We argue that this defensive process of blaming innocent victims in essence stems from self-regulatory failure. In accordance with this line of reasoning, our first experiment shows that when self-regulatory resources were depleted (i.e. in the case of high ego-depletion) before BJW threatening information describing an innocent victim of a rape crime, the effect of BJW threat on victim blaming amplified. Study 2 shows that when self-regulation was facilitated by means of self-affirmation after the BJW threatening information, the effect of BJW threat on victim blaming vanished. Taken together, our findings suggest that coping with BJW threats involve self-regulatory processes leading to more or less defensive reactions (like blaming innocent victims). When people's self-regulatory resources are depleted, they react more negatively to innocent victims when they constitute a stronger threat to the BJW. Facilitating self-regulation, by means of self-affirmation, enables people to cope with BJW threatening information, thereby inhibiting the urge to blame innocent victims.
\end{abstract}

Keywords Victim blaming - BJW threat - Self-regulation · Ego-depletion . Self-affirmation

\footnotetext{
A. Loseman $(\square)$

Department of Social and Organizational Psychology, Utrecht University, Heidelberglaan 1, 3584 CS Utrecht, The Netherlands

e-mail: a.loseman@live.nl

K. van den Bos

Utrecht University, Utrecht, The Netherlands
} 


\section{Introduction}

The world is full of contradictions and paradoxes. The tendency of people to believe that their world is a just place seems to be contrasting this view, but perhaps entails most of all a good illustration of it. People generally seem to have a need to Belief in a Just World (BJW), in which every person gets what he or she deserves (e.g. Lerner, 1977). BJW is a specific system of beliefs about the world. It satisfies at least two important human needs: the need for a consistent, predictable world and the need for a positive, benevolent world (Park \& Folkman, 1997). Perhaps most important is the promise of deservingness in BJW that reflects a fundamental psychological confidence in the ultimate reward of all the investments that people make (Callan, Shead, \& Olson, 2008; Hafer, 2000b). It is this confidence that enables people to focus on long-term goals instead of immediate gain and to have them behave according to societal norms and values instead of following their impulses, which in essence are the foundations of modern society (Hafer, 2000b).

When new information about the world is incongruent with this worldview, people are motivated to perceive this new information in a biased way or to reinterpret this information to decrease the incongruence of this new information with prior beliefs. This biased processing of information functions as a protection of important self-related needs, such as people's self-worth, as this shields people from the conclusion that their beliefs or actions were misguided. These kinds of processes are referred to as a defensive processes (Sherman \& Cohen, 2002). Research on BJW has frequently demonstrated that people react in such defensive ways to BJW threatening information. For example, when people see themselves confronted with an unjust situation like the rape of an young girl, people tend to blame the innocent victim for her ill fate. Blaming the victim helps to defend the BJW by taking care of the reinterpretation of the cause of the crime, thereby cognitively restoring justice and solving the BJW threat.

Because not all situations are equally incongruent with the BJW, the severity of the BJW threat may differ between situations as a consequence of the perceived level of justice prevalence. For example, in the situation of rape crime, having the perpetrator caught leads to higher perceptions of justice prevalence compared to when the perpetrator has not been caught (Hafer, 2000a). Furthermore, when the perpetrator has been caught, people tend to blame the innocent victim to a lesser extent than when the perpetrator has not been caught (Hafer, 2000a). Thus, varying whether a perpetrator has been caught or not is a good way to induce low versus high threats to people's BJW, and we will use this manipulation of BJW threat in the two studies we will report here. In these situations, it is the experienced justice that is assumed to lead to processes of coping with the BJW threatening information, possibly involving the blaming of innocent victims.

In social justice research, blaming innocent victims is a familiar phenomenon and a remarkable paradox, as it has especially been shown by people who are highly concerned with justice (Montada \& Lerner, 1998). From an outsiders perspective, it may be clear that these typical reactions actually contribute to a more unjust world. The secondary victimization of being blamed by others may have many negative consequences for a victim (e.g. Campbell \& Raja, 1999, 2005; Campbell, Sefl, 
Barnes, Ahrens, Wasco, Zaracgoza-Diesfeld, 1999; Pollard, 1992). The generally low report level of rape suggests that victims indeed seem to avoid secondary victimization, which indicates that blaming reactions constitute a serious societal problem (e.g. Stahl, Eek, \& Kazemi, 2010).

It may be clear that blaming an innocent victim is not a highly social desirable response to a rape crime. In general, people are very motivated to appear like reasonable creatures who behave consistently with social norms and values and blaming innocent victims is not one of them. In correspondence with this view, Lerner (1980) defined blaming as a nonrational strategy that people use to preserve a BJW. Especially, nonrational defense strategies have been the focus of research on BJW (e.g. Hafer \& Bègue, 2005) as they are strong examples of how motivated people are to maintain their Just World beliefs. For example, the tendency of people to blame innocent victims seems to illustrate the severity of the threat these people experience. Severe threats like these are likely to evoke strong aversive thoughts and emotions and therefore to involve processes of thought regulation and emotion regulation (Gailliot, Schmeichel, \& Baumeister, 2006). It is likely to assume that a threat to the BJW stands for such a strong aversive experience because it may undermine the confidence in the mere structure of one's life, thereby essentially being a threat to the self (Cohen, Aronson, \& Steele, 2000; Gailliot et al., 2006; Hafer, 2000b). Regulating the unwanted thoughts and emotions that are triggered by these significant threats involve processes of self-regulation (Gailliot et al., 2006).

Following the above line of reasoning, we would like to suggest that dealing with threats to the BJW constitutes a self-regulation process. This means that when selfregulation is impaired, the aversive threat experience will continue, making it inevitable to regulate the threat in a more awkward way, by blaming an innocent victim. On the other hand, when self-regulation is facilitated, the threat will be regulated more easily, which removes the urge to blame an innocent victim. To test these presumptions and study the self-regulation involved in the dealing with BJW threats, we will need to study the impairment and facilitation of self-regulation.

Processes of self-regulation need self-regulation resources (Baumeister, Bratlavsky, Muraven, \& Tice, 1998), which means that shortcomings in the availability of these resources lead to the insufficient functioning of self-regulation processes. The state in which self-regulation resources are depleted is known as ego-depletion (Baumeister et al., 1998). Research on ego-depletion typically tests the effect of performing one self-regulation task on performance of any subsequent task which involves self-regulation (e.g. Vohs, Baumeister, \& Ciarocco, 2005). This effect entails that ego-depletion (by means of an earlier self-regulation task) impairs following processes of self-regulation.

It is also important to note that the effect of ego-depletion can be counteracted by so-called intervention strategies (Schmeichel \& Vohs, 2009). One such psychological intervention is self-affirmation, basically the enhancement of the perceived integrity of the self (Koole, Smeets, Van Knippenberg, \& Dijksterhuis, 1999; Schmeichel \& Vohs, 2009; Steele, 1988). Self-affirmation has been shown to facilitate self-regulation in a whole range of different settings, like in cases of rumination (Koole et al., 1999), the challenge of one's beliefs (Cohen et al., 2000), threatening health messages (Sherman, Nelson, \& Steele, 2000) and mortality threat 
(Schmeichel \& Martens, 2005). Therefore, both self-affirmation and ego-depletion seem to be appropriate factors to be used in a study on the self-regulation processes of dealing with threats to the BJW.

The current paper focuses on the blaming of innocent victims following the BJW threatening information of a rape crime. We presume that dealing with BJW threats involves self-regulation processes suggesting that self-regulation failure leads to the blaming of innocent victims. We will study the effect of impairment (by means of ego-depletion; Study 1) and facilitation (by means of self-affirmation; Study 2) of self-regulation of a BJW threat that is either high (perpetrator not caught) or low (perpetrator caught) on the blaming of an innocent victim. We hypothesize that egodepletion will lead to the amplification of the blaming of the rape victim: Blaming reactions will be stronger when the threat is high compared to when the threat is low. We also hypothesize that self-affirmation will have a diminishing effect on the blaming of the rape victim: The difference in blaming reactions when the threat is high compared to when the threat is low will attenuate.

In accordance with research on ego-depletion (e.g. Gailliot et al., 2006) and selfaffirmation (e.g. Schmeichel \& Vohs, 2009), the two studies focus on different parts of the self-regulation process. In Study 1, ego-depletion will be induced before the BJW threatening information. In Study 2, self-affirmation will be induced after the BJW threatening information. In Study 2, we will examine our predictions in a student sample and in Study 1 we will test our predictions in a non-student population.

\section{Study 1}

Method

\section{Participants and Design}

One-hundred-and-twelve participants (51 men and 61 women, with ages varying between 18 and 57 years and with a mean age of 28 years and 4 months, $\mathrm{SD}=9$ years and 11 months) walking in the city centre of Rotterdam participated in the study. They were randomly assigned to one of the four groups of our 2 (egodepletion: high vs. low) $\times 2$ (BJW threat: high vs. low) factorial design.

\section{Experimental Procedure}

People walking in the city centre of Rotterdam were asked whether they were willing to participate in two ostensibly unrelated studies. The first study was introduced as a study on language processing. Next, ego-depletion was manipulated using the manipulation developed by Muraven, Tice, \& Baumeister (1998) by instructing the participants to cross out all letters "e" in a statistical text. Participants had to do the same in a second statistical text in the low ego-depletion condition. In the high ego-depletion condition, participants were instructed that instead of just crossing out the letters " $\mathrm{e}$ " in the second text, they had only to cross 
out the letters "e" when they did not stand next to another vowel or were separated of another vowel by just one consonant.

Next, the second study started, which was introduced as a study on perceptions of media information. Participants read a newspaper article that ostensibly was published that same day in a local newspaper. Participants who said to know the newspaper article or to be familiar with the news in another way were excluded from the data analyses. ${ }^{1}$ The article described an assault of a student named Marieke with an age of 24-year old at the University of Rotterdam and the assault took place in the city centre of Rotterdam. BJW threat was manipulated following Hafer (2000a) by stating that the perpetrator had been arrested (low BJW threat) or not (high BJW threat).

After reading this newspaper article, dependent variables were measured by asking the participants to what extent they thought that what happened to Marieke had been caused by how she behaved $(1=$ very weakly, $7=$ very strongly $)$, Marieke was to blame to what had happened to her $(1=$ very weakly, $7=$ very strongly), Marieke had behaved in her situation irresponsibly ( $1=$ very weakly, $7=$ very strongly $)$, Marieke had behaved very carelessly $(1=$ very weakly, 7 = very strongly), and to what extent they felt sorry for Marieke $(1=$ very weakly, 7 = very strongly). After recoding the answers to the last question, participants' answers to these five questions were averaged to a reliable scale of victim blaming (alpha $=.77$ ).

The manipulation of BJW threat was checked by asking the participants to what extent they thought justice had prevailed in the situation described in the newspaper article $(1=$ very weakly, $7=$ very strongly $)$. Finally, participants were debriefed and thanked for their participation.

\section{Results}

\section{Justice Prevalence}

A $2 \times 2$ analysis of variance (ANOVA) on the manipulation check of BJW threat with ego-depletion and BJW threat as independent variables and the perceived justice prevalence as dependent variable showed a main effect of BJW threat only, $F(1,108)=23.26, p<.001$. Participants judged the situation in which the perpetrator had been arrested as a situation in which justice had prevailed to a higher extent $(M=4.12, \mathrm{SD}=1.74)$ than the situation in which the perpetrator had not been arrested $(M=2.62, \mathrm{SD}=1.48)$. This showed that the manipulation of BJW threat was successful.

\section{Victim Blaming}

A $2 \times 2$ ANOVA with ego-depletion and BJW threat as independent variables and victim blaming as dependent variable showed a main effect of BJW threat,

\footnotetext{
${ }^{1}$ Although it was not possible that participants really were familiar with this news report—as it was a fake report - the idea that they knew it and had associations with it, may have affected their responses to the information. Therefore, we decided to exclude these participants from the data analyses.
} 
$F(1,108)=6.44, p<.05, \eta_{\mathrm{p}}^{2}=.06$. This main effect of BJW threat was qualified by the predicted interaction effect, $F(1,108)=8.46, p<.01, \eta_{\mathrm{p}}^{2}=.07$. Means and standard deviations are presented in Table 1. As expected, there was a significant effect of BJW threat when participants were in the high ego-depletion condition, $F(1,109)=14.46, p<.001, \eta_{\mathrm{p}}^{2}=.12$. Thus, after performing the difficult "e" crossing task, participants blamed the victim more when the perpetrator had not been arrested than when the perpetrator had been arrested. In the low ego-depletion condition, there was no significant difference in blaming the victim between the low threat and the high threat condition, $F<1$. We will get back to this finding in the "Discussion".

There was also a simple main effect of ego-depletion in the high threat condition, $F(1,109)=4.83, p<.05, \eta_{\mathrm{p}}^{2}=.04$. Thus, when the perpetrator had not been arrested, participants blamed the victim more when they performed the difficult " $\mathrm{e}$ " crossing task than when they performed the more simple "e" crossing task. When the perpetrator had been arrested, however, there was only a marginally significant simple main effect of ego-depletion, $F(1,109)=3.14, p=.079$.

\section{Discussion}

Our first study shows that when regulation resources were depleted, participants blamed the innocent victim more when the perpetrator had not been arrested than when the perpetrator had been arrested. When the threat to the BJW was higher, they showed stronger defensive reactions to this threat, showing they were less able to regulate this threat. When participants had enough resources left for selfregulation, they did not show these defensive reactions.

These results suggest that dealing with a threat to the BJW is a form of selfregulation which needs regulation resources. The results in the control conditionparticipants who were not highly depleted did not react more defensively when the BJW threat was higher-suggest that, amongst other explanations, it may very well be possible that the low ego-depletion task (crossing out all letters "e" in a text) was so easy that participants felt really good about themselves. In this sense, the task may have been self-affirmative and may have facilitated self-regulation (e.g. Gailliot, Baumeister, \& Mead, 2008). Perhaps, this self-regulation facilitation enabled participants to regulate the threat to such an extent that it disconnected the

Table 1 Victim blaming as influenced by BJW threat and ego-depletion

\begin{tabular}{llllll}
\hline & \multicolumn{2}{l}{ Low BJW threat } & & & \multicolumn{2}{l}{ High BJW threat } \\
\cline { 2 - 3 } & $M$ & SD & & $M$ & SD \\
\hline Low ego-depletion & 2.07 & 0.90 & & 2.01 & 1.03 \\
High ego-depletion & 1.66 & 0.65 & & 2.62 & 1.08 \\
\hline
\end{tabular}

Means are on 7-point scales, with higher values indicating higher levels of blaming. Means with no subscripts in common differ significantly $(p<.05)$, as indicated by a least significant difference test for multiple comparisons between means 
severity of the BJW threat with the urge to blame the innocent victim. We will go further into that in the "General Discussion" of the current paper. In Study 2, we will focus on the facilitation of the presumed self-regulation process of dealing with BJW threatening information by studying the effect of self-affirmation on blaming an innocent victim when the perpetrator had been arrested versus when he had not been arrested. We hypothesize that self-affirmation will have a diminishing effect on the blaming of the rape victim: The difference in blaming reactions when the threat is high compared to when the threat is low will attenuate. We conducted Study 2 in a student population to make the BJW threat even more relevant, as we expect students to identify stronger with the victim Maaike.

\section{Study 2}

\section{Method}

\section{Participants and Design}

One-hundred-and-twelve students at Utrecht University (66 men and 46 women) with ages varying between 17 and 27 years, with a mean age of nearly 21-year old ( $\mathrm{SD}=2$ years and 1 month) participated in the study. They were randomly assigned to one of the four groups of our 2 (BJW threat: high vs. low) $\times 2$ (selfaffirmation: yes vs. control) factorial design.

\section{Experimental Procedure}

Participants were approached at the university campus and asked whether they would like to participate in a study on the perception of media information. They read a newspaper article that ostensibly was published that same day in a local newspaper. Participants who said to be familiar with the news were excluded from the data analyses. The article was similar to Study 1, except that the victim was a student named Maaike who lived in the city centre of Utrecht. BJW threat was again manipulated by stating in the article that the perpetrator had been arrested in the low threat condition and in the high threat condition that he had not been arrested yet.

After reading the newspaper article, participants were told that before answering some questions about this article, they would first do a distraction task. At this moment, the manipulation of self-affirmation was induced. In the self-affirmation condition, participants were asked to write down three positive characteristics of themselves. In the control condition, participants were asked to write down three brands of detergent. After this, dependent variables were measured by asking the participants the same questions as in Study 1. Participants' answers on these items were again averaged to a reliable scale of victim blaming (alpha $=.79$ ). The manipulation of BJW threat was checked in the same way as in Study 1, namely, by asking the participants to what extent they thought justice had prevailed in the situation described in the newspaper article $(1=$ very weakly, $7=$ very strongly $)$. Finally, participants were debriefed and thanked for participation. 
Table 2 Victim blaming as influenced by BJW threat and self-affirmation

\begin{tabular}{llllll}
\hline & \multicolumn{2}{l}{ Low BJW threat } & & \multicolumn{2}{l}{ High BJW threat } \\
\cline { 2 - 3 } \cline { 5 - 6 } & $M$ & SD & & $M$ & SD \\
\hline Self-affirmation & 2.16 & 1.18 & 2.04 & 1.12 \\
No self-affirmation & 1.76 & 0.87 & 2.46 & 1.06 \\
\hline
\end{tabular}

Means are on 7-point scales, with higher values indicating higher levels of blaming. Means with no subscripts in common differ significantly $(p<.05)$, as indicated by a least significant difference test for multiple comparisons between means

\section{Results}

\section{Justice Prevalence}

A $2 \times 2$ ANOVA on the manipulation check of BJW threat with self-affirmation and BJW threat as independent variables and perceived justice prevalence as dependent variable showed a main effect of BJW threat, $F(1,108)=15.09$, $p<.001$. Participants judged the situation in which the perpetrator had been arrested as a situation in which justice had prevailed to a higher extent $(M=3.56$, $\mathrm{SD}=1.93$ ) than the situation in which the perpetrator had not been arrested $(M=2.29, \mathrm{SD}=1.56)^{2}$ This showed that the manipulation of BJW threat was successful.

\section{Victim Blaming}

A $2 \times 2$ ANOVA on the reactions on the victim scale revealed the expected interaction effect between BJW threat and self-affirmation, $F(1,108)=4.11$, $p<.05, \eta_{\mathrm{p}}^{2}=.04$. Table 2 reports the appropriate means and standard deviations. Participants in the control condition showed the expected simple main effect of BJW threat, $F(1,109)=6.01, p<.05, \eta_{\mathrm{p}}^{2}=.05$. When participants had listed three brands of detergent, participants blamed the victim significantly more when the perpetrator had not been arrested than when the perpetrator had been arrested. When participants had the opportunity to affirm themselves, however, this simple main effect of BJW threat on blaming the victim was statistically not significant. Selfaffirmation caused no significant differences in victim blaming within the high and the low BJW threat conditions.

\section{General Discussion}

Two studies have been conducted to test the presumption that coping with a threat to the belief that the world is a just place constitutes a self-regulation process.

\footnotetext{
2 The low means for perceived justice prevalence suggest that we were successful in making the BJW threat more threatening. Fortunately, the coinciding smaller difference in means between the two situations was still significant.
} 
Participants were confronted with a reported event of an innocent young woman who fell victim of a rape crime, which generally entails a threat to the idea that in this world everybody gets what he or she deserves. The results of the current studies demonstrated that when self-regulation resources were depleted, participants tended to blame the innocent victim more for her ill fate when the situation constituted a stronger threat to the BJW (i.e. the perpetrator had not been caught) compared to when this BJW threat was a bit weaker (i.e. the perpetrator had been caught). Selfaffirmation-known for facilitating self-regulation—caused the blaming of innocent victims to attenuate, leading participants not to blame the victim more when the BJW threat was higher. These results strongly support the idea of the self-regulation basis of coping with BJW threats, showing both the impairment of self-regulation caused by ego-depletion as the facilitating role of self-affirmation.

As we mentioned in the "Discussion" of Study 1, there was no effect of BJW threat on blaming in the low ego-depletion (i.e. control) condition. This is remarkable, because the blaming of an innocent victim is a frequently used measure of the experienced BJW threat, usually showing stronger blaming reactions when BJW threat is higher. There may be several possible explanations of the current deviation of this regular finding. Most important is the successful induction of BJW threat. We induced BJW threat by means of the manipulation of justice prevalence which is based on previous experimental research on BJW where it is considered to be an effective manipulation of BJW threat (e.g. Hafer, 2000a). The current manipulation check shows that the manipulation had the intended effect by displaying that participants experienced the high BJW threat situation (perpetrator was not caught) as being less just compared to the low BJW threat situation (perpetrator was caught). ${ }^{3}$ Furthermore, Study 2 shows the predicted effects of BJW threat on blaming. Taken together, there are no clear indications of an unsuccessful BJW threat induction. It may therefore be interesting to consider the manipulation of low ego-depletion instead. We could suggest that this task (crossing out all "e's" in a text) can be seen as a relatively easy achievement task, which may implicate that participants used this task for self-affirmation. However, the particular task was not administered after the induction of BJW threat, like the self-affirmation manipulation in Study 2, but instead before the BJW threat, to enable comparisons with the high ego-depletion condition.

Because research on self-affirmation is not completely consistent in the sequence of manipulations in the self-regulation process to be studied (see, e.g. Koole et al., 1999, induced self-affirmation before the self-regulation task), it is possible that our manipulation of low ego-depletion manipulation may have had a self-affirmative effect and facilitated the process of dealing with a threat to the BJW. Possibly, this may explain the absence of any effects of BJW threat on blaming reactions in the

\footnotetext{
3 It has been suggested that justice judgments need cognitive elaboration and involve the incorporation of justice principles (Van den Bos, Peters, Bobocel, \& Ybema, 2006) which means that these judgments are less susceptible to motivational processes. It remains unclear whether it is this insusceptibility of justice judgments by which blaming responses are not able to affect the judgments on prevailed justice or whether the blaming responses are in fact not successful in restoring justice in the situations. Future research needs to find out which judgments are involved in the BJW threat coping processes, and in what way they are involved.
} 
low ego-depletion condition. Since research on ego-depletion typically compares the means in the low ego-depletion condition with the means in the high egodepletion condition, the study by Muraven et al. (1998), which originally used the current ego-depletion manipulation, cannot clarify possible self-affirming aspects of the low ego-depletion manipulation task. However, other possible explanations for the current results in the low ego-depletion condition remain, like the possibility that the specific manipulation task may have distracted the participants from the BJW threatening information. Participants in the low ego-depletion condition had to execute the same task twice, which may have felt strange for participants and triggered processes of sense making, distracting participants from the subsequent BJW threatening information. Of course, all of these explanations are highly speculative and future research is needed to come to further insights into the implementation of ego-depletion manipulations in BJW research.

The current research provides first support for the blaming of innocent victims as a consequence of the preceding self-regulation processes of dealing with BJW threats. A next step that future research may take may be to get more detailed insights in what part of the coping process is being measured. For example, it may be possible that self-regulation is involved mainly in controlling people's reactions to the BJW threatening situation instead of reducing the urge of these reactions by regulating the threat. Social goals like doing well or impression management occupy self-regulation resources (Gailliot et al., 2008; Vohs et al., 2005) and the expression of social undesirable reactions (e.g. the blaming of an innocent victim) only takes place when people do not have access to resources needed to override the tendency to express these reactions. However, people regularly do so, as the blaming of innocent victims have been frequently measured in BJW research (e.g. Hafer \& Bègue, 2005). We think this may be explained by the depletion of selfregulation resources as a consequence of the self-regulation process of dealing with threats to the BJW. This means that when people just have dealt with a BJW threat they will be less able to self-control. Furthermore, we would like to suggest that the success of self-regulation determines whether there is an urge to blame an innocent victim and whether people will show these blaming reactions. In case of selfregulation failure, for example, when no self-regulation resources are available due to ego-depletion or when the threat is too high, people may want to engage in the blaming of innocent victims. However, when self-regulation is successful, for example when it is facilitated by self-affirmation, there will be no need left for blaming and hence it is much more likely that people will not blame innocent victims. According to this reasoning, other ways of self-regulation are preferred to the blaming of innocent victims. This may follow from the socially undesirability of the specific response, but it is also unclear whether blaming responses are actually capable to successfully regulate BJW threats. Future research is needed to find out the specifics about the involvement of the blaming of innocent victims in the processes of coping with BJW threats.

We note explicitly that not only ego-depletion or self-affirmation determine the failure or success of self-regulation. Different kinds of BJW inconsistent information may trigger different levels of BJW threat. Some BJW threats are strong and will lead to depletion and in case of self-regulation failure to the blaming of 
innocent victims. Some BJW threats are weaker and will not lead to depletion and will not have innocent victims being blamed for their ill fate. The stronger the BJW threat, the greater the challenge of regulating the threat, the more self-regulation resources are needed and the higher the chance people tend to blame innocent victims. BJW threat may also induce cognitive load, which has been suggested to have the same effects as ego-depletion (see, e.g. Vosgerau, Bruyneel, Dhar, Wertenbroch, 2008) and has been shown to facilitate irrational justice-related reactions as well (Callan, Sutton, \& Dovale, 2010). However, cognitive load cannot replace our line of reasoning on self-regulation, at is provides no equivalence to self-affirmation. The specific processes and effects that may be induced by BJW threats need to be investigated in future research. The current research used egodepletion and self-affirmation in rather straightforward ways, as the factors that impair and facilitate self-regulation. However, self-affirmation seems to have interesting characteristics besides the facilitation of self-regulation. While egodepletion seems to do what it has been suggested to do, namely, the depletion of self-regulation resources, self-affirmation is the counterpart of ego-depletion in facilitating self-regulation, but seems not to be just the replenishment of depleted resources (Schmeichel \& Vohs, 2009). One of the effects of self-affirmation that may come closest to the definition of self-affirmation is the presumed enhancement of self-competence that lowers personal threat, supported by findings showing that self-affirmation leads to a more objective-instead of defensive-perception of threatening health messages (Correll, Spencer, \& Zanna, 2004). In line with this, self-affirmation also leads to lower worldview defense and even mortality salience (Schmeichel \& Martens, 2005), providing support for our idea that, in the current research, self-affirmation is mainly involved in dealing with BJW threatening information and not in simply enhancing self-control over people's blaming reactions. However, most interesting for the current purposes is the idea that selfaffirmation promotes higher-level or abstract mental construals that helps to overcome concrete problems by focusing on more abstract and long-term goals (Schmeichel \& Vohs, 2009). The BJW seems to resemble such an abstract mental construal as it consists of the beliefs about deservingness and the value of attaining to long-term goals. Schmeichel \& Vohs (2009) argue that self-affirmation may help people shift from a focus on a concrete threat triggered by a specific situation (e.g. a rape crime) to a focus on more abstract values and goals in life, and that this shift helps them to overcome the threat. Future research is needed to shed more light on the precise role that self-affirmation may play in dealing with BJW threats and in the blaming of innocent victims.

The self-regulation basis of dealing with BJW threats further illustrates the importance of BJW in people's lives. As Lerner (1980) convincingly argued, people seem to be highly concerned with justice. However, whether this justice refers to objective, non self-related issues or whether it mainly involves issues related to the self, has been an ongoing debate (e.g. Ham \& Van den Bos, 2008). The current studies aim to support a self-related standpoint by showing that self-regulation processes are involved in dealing with a threat to the BJW. These findings suggest that situations that confront people with BJW inconsistent information, reminding them of an unjust world, are experienced as threats and may trigger aversive thoughts and emotions. 
Furthermore, the need to maintain the BJW seems to be high, just like the urge to get rid of threat-related thoughts and emotions may be, which ultimately may override social goals like not blaming innocent victims. In line with this reasoning, and based on the current findings as well as on previous BJW research, it may be a firm conclusion that the BJW is very important to the self.

\section{Conclusions}

In the current paper, we introduced a self-regulation perspective on dealing with threats to the BJW. We argued that because BJW defensive reactions are regularly shown even when they are social undesirable, BJW must be very important to people. In general, the regulation of significant threats involves self-regulation processes and may be affected by the factors involved in such processes. Two studies have supported the self-regulation basis of dealing with BJW threats by showing that ego-depletion leads to the amplification of the blaming of an innocent victim of a rape crime while self-affirmation leads to the attenuation of the blaming of this innocent victim. The current findings may help people to deal with BJW threats and to overcome the harmful blaming of innocent victims by making them aware of the process, the impairing role of ego-depletion and the facilitating role of self-affirmation. In the end, this would make the world more just than simply by believing in it.

Acknowledgments This research was supported by a VICI Innovational Research Grant (453-03-603); obtained from the Netherlands Organization for Scientific Research (NWO). We thank Tom Ruijs for his assistance with the data gathering of both studies.

Open Access This article is distributed under the terms of the Creative Commons Attribution License which permits any use, distribution, and reproduction in any medium, provided the original author(s) and the source are credited.

\section{References}

Baumeister, R. F., Bratlavsky, E., Muraven, M., \& Tice, D. M. (1998). Ego-depletion. Is the active self a limited resource? Journal of Personality and Social Psychology, 74(5), 1252-1265.

Callan, M. J., Shead, N. W., \& Olson, J. M. (2008). Foregoing the labor for the fruits: The effect of just world threat on the desire for immediate monetary rewards. Journal of Experimental Social Psychology, 45, 246-249.

Callan, M. J., Sutton, R., \& Dovale, C. (2010). When deserving translates into causing: The effects of cognitive load on immanent justice reasoning. Journal of Experimental Social Psychology, 46, 1097-1100.

Campbell, R., \& Raja, S. (1999). Secondary victimization of rape victims: Insights from mental health professionals who treat survivors of violence. Violence Victomology, 14, 261-275.

Campbell, R., \& Raja, S. (2005). The sexual assault and secondary victimization of female veterans: Help-seeking experiences with military and civilian social systems. Psychology of Women Quarterly, 29, 97-106.

Campbell, R., Sefl, T., Barnes, H. E., Ahrens, C. E., Wasco, S. M., \& Zaracgoza-Diesfeld, Y. (1999). Community services for rape survivors: Enhancing psychological well-being or increasing trauma? Journal of Consulting and Clinical Psychology, 67, 847-858. 
Cohen, G. L., Aronson, J., \& Steele, C. M. (2000). When beliefs yield to evidence: Reducing biased evaluation by affirming the self. Personality and Social Psychology Bulletin, 26, 1151-1164.

Correll, J., Spencer, S. J., \& Zanna, M. P. (2004). An affirmed self and an open mind: Self-affirmation and sensitivity to argument strength. Journal of Experimental Social Psychology, 40, 350-356.

Gailliot, M. T., Baumeister, R. F., \& Mead, N. (2008). Self-regulation. In O. P. John, R. W. Robins, \& L. A. Pervin (Eds.), Handbook of personality: Theory and research (3rd ed., pp. 472-491). New York: Guilford.

Gailliot, M. T., Schmeichel, B. J., \& Baumeister, R. F. (2006). Self-regulatory processes defend against the threat of death: Effects of self-control depletion and trait self-control on thoughts and fears of dying. Journal of Personality and Social Psychology, 91, 49-62.

Hafer, C. L. (2000a). Do innocent victims threaten the Belief in a Just World? Evidence from a modified Stroop task. Journal of Personality and Social Psychology, 79, 165-173.

Hafer, C. L. (2000b). Investment in long-term goals and commitment to just means drive the need to believe in a just world. Personality and Social Psychology Bulletin, 26, 1059-1073.

Hafer, C. L., \& Bègue, L. (2005). Experimental research on just-world theory. Problems, developments, and future challenges. Psychological Bulletin, 131, 128-167.

Ham, J., \& Van den Bos, K. (2008). Not fair for me! The influence of personal relevance on social justice inferences. Journal of Experimental Social Psychology, 44, 699-705.

Koole, S. L., Smeets, K., Van Knippenberg, A., \& Dijksterhuis, A. (1999). The cessation of rumination through self-affirmation. Journal of Personality and Social Psychology, 77, 111-125.

Lerner, M. J. (1977). The justice motive: Some hypotheses as to its origins and forms. Journal of Personality, 45, 1-52.

Lerner, M. J. (1980). The belief in a just world: A fundamental delusion. New York: Plenum Press.

Montada, L., \& Lerner, M. J. (Eds.). (1998). Responses to victimizations and Belief in a Just World. New York: Plenum Press.

Muraven, M., Tice, D. M., \& Baumeister, R. F. (1998). Self-control as limited resource: Regulatory depletion patterns. Journal of Personality and Social Psychology, 74, 774-789.

Park, C. L., \& Folkman, S. (1997). Meaning in the context of stress and coping. Review of General Psychology, 1, 115-144.

Pollard, P. (1992). Judgements about victims and attackers in depicted rapes: A review. British Journal of Social Psychology, 31, 307-326.

Schmeichel, B. J., \& Martens, A. (2005). Self-affirmation and mortality salience: Affirming values reduces worldview defense and death-thought accessibility. Personality and Social Psychology Bulletin, 31, 658-667.

Schmeichel, B. J., \& Vohs, K. (2009). Self-affirmation and self-control: Affirming core values counteracts ego depletion. Journal of Personality and Social Psychology, 96, 770-782.

Sherman, D. K., \& Cohen, G. L. (2002). Accepting threatening information: Self-affirmation and the reduction of defensive biases. Current Directions in Psychological Science, 11, 119-123.

Sherman, D. K., Nelson, L. D., \& Steele, C. M. (2000). Do messages about health risks threaten the self? Increasing the acceptance of threatening health messages via self-affirmation. Personality and Social Psychology Bulletin, 26, 1046-1058.

Stahl, T., Eek, D., \& Kazemi, A. (2010). Rape victim blaming as system justification: The role of gender and activation of complementary stereotypes. Social Justice Research, 23, 239-258.

Steele, C. M. (1988). The psychology of self-affirmation: Sustaining the integrity of the self. In L. Berkowitz (Ed.), Advances in experimental social psychology (Vol. 21, pp. 261-302). New York: Academic Press.

Van den Bos, K., Peters, S. L., Bobocel, D. R., \& Ybema, J. F. (2006). On preferences and doing the right thing: Satisfaction with advantageous inequity when cognitive processing is limited. Journal of Experimental Social Psychology, 42, 273-289.

Vohs, K. D., Baumeister, R. F., \& Ciarocco, N. J. (2005). Self-regulation and self-presentation. Regulatory resource depletion impairs impression management and effortful self-presentation depletes regulatory resources. Journal of Personality and Social Psychology, 88, 632-657.

Vosgerau, J., Bruyneel, S., Dhar, R., \& Wertenbroch, K. (2008). Ego depletion and cognitive load: Same or different constructs? Advances in Consumer Research, 35, 217-220. 